\title{
Arginine Adjunctive Therapy in Active Tuberculosis
}

\author{
Aliasghar Farazi, ${ }^{1,2}$ Omid Shafaat, ${ }^{3}$ Masoomeh Sofian,, ${ }^{1,2}$ and Manijeh Kahbazi ${ }^{2}$ \\ ${ }^{1}$ Department of Infectious Disease, School of Medicine, Arak University of Medical Sciences, Arak 38159 34798, Iran \\ ${ }^{2}$ Tuberculosis and Pediatric Infectious Diseases Research Center, Arak University of Medical Sciences, Arak 38159 34798, Iran \\ ${ }^{3}$ School of Medicine, Arak University of Medical Sciences, Arak 38159 34798, Iran
}

Correspondence should be addressed to Aliasghar Farazi; farazialiasghar@yahoo.com

Received 12 December 2014; Revised 21 January 2015; Accepted 21 January 2015

Academic Editor: T. Ottenhoff

Copyright (C) 2015 Aliasghar Farazi et al. This is an open access article distributed under the Creative Commons Attribution License, which permits unrestricted use, distribution, and reproduction in any medium, provided the original work is properly cited.

\begin{abstract}
Background. Dietary supplementation has been used as a mechanism to augment the immune system. Adjunctive therapy with L-arginine has the potential to improve outcomes in active tuberculosis. Methods. In a randomized clinical trial 63 participants with smear-positive pulmonary tuberculosis in Markazi Province of Iran were given arginine or placebo for 4 weeks in addition to conventional chemotherapy. The final treatment success, sputum conversion, weight gain, and clinical symptoms after one and two months were considered as primary outcomes and secondary outcomes were ESR, CRP, and Hg. Data were collected and analyzed with SPSS software (ver. 18). Results. Arginine supplementation reduced constitutional symptoms $(P=0.032)$ in patients with smear-positive TB at the end of the first month of treatment. Arginine treated patients had significantly increased BMI at the end of the first and second months of treatment $(P=0.032$ and $P=0.04)$ and a reduced CRP at the end of the first month of treatment $(P=0.03)$ versus placebo group. Conclusion. Arginine is useful as an adjunctive therapy in patients with active tuberculosis, in which the effects are more likely mediated by the increased production of nitric oxide and improved constitutional symptoms and weight gain. This trial is registered with Clinical Trials Registry of Iran: IRCT201211179855N2.
\end{abstract}

\section{Introduction}

Tuberculosis (TB) is an important global health problem. About one-third of the population is estimated to be infected with M. tuberculosis. People with latent TB infection (LTBI) do not have symptoms of $\mathrm{TB}$ and are not infectious, but they are at risk of developing active disease and becoming infectious. Studies show that $5-20 \%$ of those infected will develop active TB at some point in their lifetime, with the majority developing TB disease within 2-5 years of the initial infection. In 2012, an estimated 8.6 million people developed TB and 1.3 million died from the disease [1]. Arginine, first discovered over 100 years ago, is a basic amino acid naturally ingested in our diets at a rate of $3-5 \mathrm{~g} / \mathrm{d}$ [2]. Arginine is particularly rich in certain food products, such as meats and nuts. Arginine can be synthesized endogenously but, in children and in people with certain conditions (e.g., infection, trauma), arginine synthesis may become compromised. It should be noted that groundnuts (peanuts) contain $1 \mathrm{~g}$ of arginine per $30 \mathrm{~g}$ of biomass and they are affordable and readily available worldwide [3,4]. Arginine as a semiessential amino acid was found to be necessary for adequate wound healing [5-7]. These observations were summarized in the statement that arginine was a "conditionally essential amino acid" which should be supplemented at times of physical stress such as after surgery or trauma $[8,9]$.

Numerous reports based on animal models suggest that nitric oxide is important for host resistance during the acute phase of TB $[10,11]$. The role of nitric oxide in humans is controversial, although recent findings suggeste its role in human TB $[12,13]$. Inducible nitric oxide synthase catalyzes the synthesis of nitric oxide and citrulline from L-arginine in macrophages activated by cytokines, such as TNF- $\alpha$ and IFN- $\gamma$. Nitric oxide is highly unstable and decays to its stable end products nitrate and nitrite, which are eliminated in the urine in as much as malnutrition, and reduced food intakes are associated with TB [14]. In a randomized clinical trial of TB patients without HIV infection, supplement therapy by arginine resulted in higher sputum conversion rates, faster reduction of symptoms (e.g., cough), and increase in 
weight gain. However, these improvements were not seen in patients with HIV in the same trial or another trial $[15,16]$. A placebo-controlled randomized trial in central province of Iran was conducted to ascertain whether adjuvant arginine supplementation can improve the clinical outcome of pulmonary $\mathrm{TB}$.

\section{Materials and Methods}

2.1. Patients. We designed a clinical randomized placebocontrolled trial in new cases of smear-positive TB that were recruited with informed consent from December 2012 to May 2014 at the Direct Observed Treatment Short-Course (DOTS) Clinics in Markazi province. The inclusion criteria were age of $\geq 15$ years and smear-positive pulmonary $\mathrm{TB}$, as recommended by the World Health Organization (WHO) for DOTS. The exclusion criteria were hospitalization, pregnancy, clinical signs of any comorbidity (such as diabetes mellitus, malignancy, hepatic or renal failure, $\mathrm{HIV}^{+}$, etc.) according to physician's judgement and patient's medical documents, patients who received L-arginine supplement during the past month, and allergic reactions to L-arginine. Smear positivity was defined as two of three positive morning sputum samples or one of three positive with a chest radiograph and clinical symptoms suggestive of pulmonary TB. Treatment success according to WHO guidelines was defined as the sum of the cases that were cured and that completed treatment. Sputum smear was recorded at the beginning, one and two months after treatment. Body mass index was recorded at baseline, one and two months after beginning treatment. Blood samples for C-reactive protein (CRP was measured by latex agglutination tests), Erythrocyte Sedimentation Rate (ESR by Westergren method), and hemoglobin concentration (Hgb was measured by hematology analyzer Sysmex K1000) were obtained at baseline, one and two months after starting treatment. Using a standard form, patients were initially interviewed regarding duration of clinical symptoms, one and two months later concerning the presence or absence of symptoms (cough, constitutional symptoms, and body mass index). All laboratory tests were measured in one laboratory with the same personnel and calibrated equipment and all clinical signs and symptoms were measured by one person.

2.2. Treatment Regimes. All treatment was done on an outpatient basis, according to the WHO recommendations. The chemotherapy consisted of isoniazid, pyrazinamide, rifampicin, and ethambutol during the intensive phase of 2 months followed by isoniazid and ethambutol to 6 months.

At initiation of anti-TB therapy, patients with TB were assigned by randomization into supplementation with identical capsules of L-arginine (Karen Pharma \& Food Supplement Co., Iran) which contains $1000 \mathrm{mg}$ pure L-arginine hydrochloride or placebo which contains $1000 \mathrm{mg}$ sugar twice daily administered orally for 30 days in accordance with previous studies $[15,16]$. The final treatment success, sputum conversion, weight gain, and clinical symptoms after one and two months were considered as primary outcomes and secondary outcomes were ESR, CRP, and Hgb.

2.3. Design and Statistical Methods. Sample size was calculated based on the published data of a resembling trial [17]. The formula of calculating sample size was

$$
n=\frac{\left(Z_{\alpha / 2}+Z_{\beta}\right)^{2} \times\left[p_{1}\left(1-p_{1}\right)+p_{2}\left(1-p_{2}\right)\right]}{\left(p_{1}-p_{2}\right)^{2}}
$$

where $p_{1}=\% 83.8$ and $p_{2}=\% 53.1\left(p_{1}=\right.$ cure rate in supplemented group and $p_{2}=$ proportion of cure rate in placebo group). With a power of $85 \%$ and $\alpha$ level of 0.10 , the sample size was calculated to be 29 for each group and taking into account $15 \%$ dropout, a total of 68 patients were enrolled in two groups of case and control. Patients were randomly assigned to either the arginine group or the placebo group. The randomization was 1:1 for the 2 groups and was performed by using random number tables, for the two assign regimens (Figure 1). Preparation of the randomization envelopes was performed by a member of the staff who was not directly involved in the study and a sealed copy of the treatment code was kept by the project leader until all data had been collected and analyzed.

Analyses were conducted using SPSS software (ver. 18) according to a prespecified plan. Outcomes were analyzed according to the arms to which the participant was originally assigned. Statistical analysis was performed by calculation of mean \pm standard deviation; ANOVA (differences between group means), $t$-test and Mann-Whitney $U$ test (differences between baseline and follow-up of all parameters in each group), and Fisher's exact test and chi-square test (comparison of categorical variables) were used; $P$ values of $<0.05$ were significant.

\section{Results}

Of 68 eligible patients, 63 sputum AFB-positive patients were included in the study and 5 were excluded (two males were transferred to another province; one male was $\mathrm{HIV}^{+}$; one female patient due to drug-induced hepatitis; a female patient used steroid). Of the 63 patients that completed treatment, 32 patients were randomly assigned to the arginine group and 31 to the placebo group. In trial group $46.9 \%$ and control group $51.6 \%$ were male. The mean age of the trial group was $51.9 \pm 22.8$ and median was 52 years, in the control group mean age was $52.3 \pm 21.7$ and the median was 53 years. Sociodemographic characteristics of the study show that $41.3 \%$ of them belong to rural areas while $58.7 \%$ are from urban sector. There were no significant differences in any of the baseline characteristics between the arginine and placebo groups, including gender, age, body mass index (BMI), and laboratory characteristics (Hgb, ESR, and CRP) at the beginning of treatment. Baseline patient characteristics in two groups are shown in Table 1.

Arginine supplementation reduced constitutional symptoms $(P=0.032)$ at the end of the first month of treatment. Arginine treated patients had significantly increased BMI at 


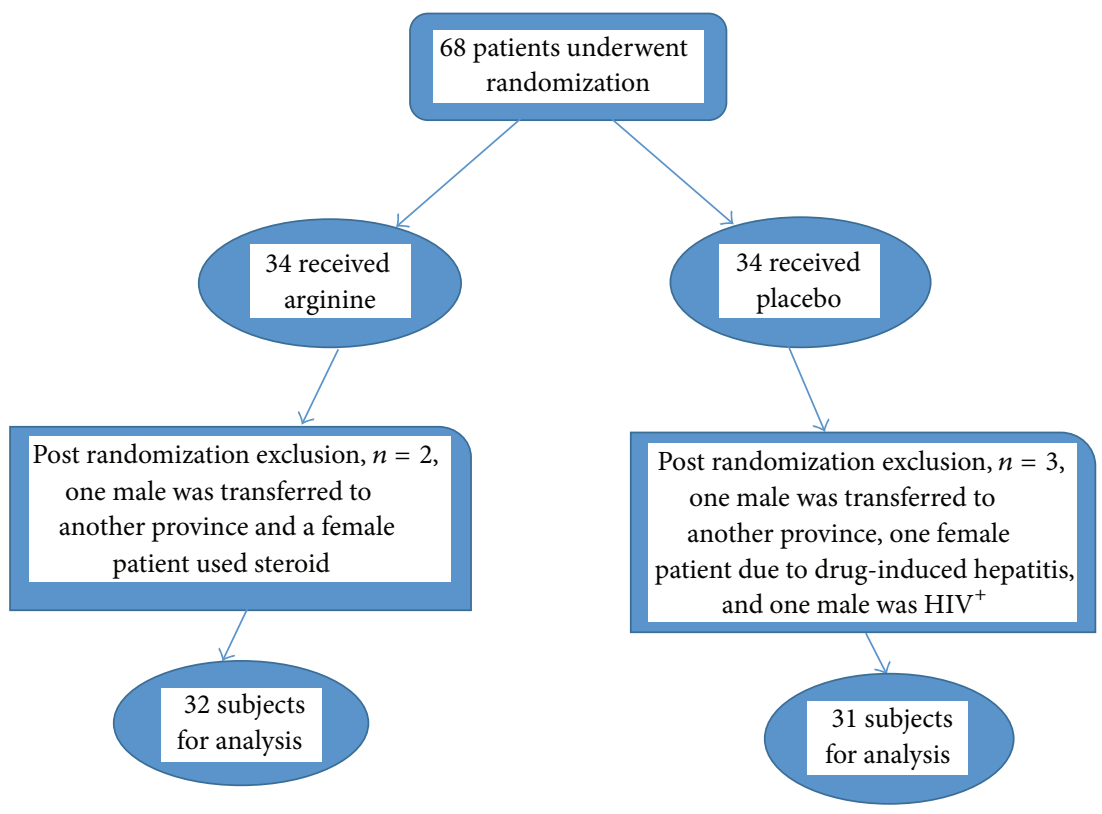

Figure 1: Study flow chart.

TABLE 1: Clinical and laboratory findings in arginine and placebo group before treatment.

\begin{tabular}{lccc}
\hline \multirow{2}{*}{ Sign and symptom } & \multicolumn{2}{c}{ Group } & \\
& $N=32(\%)$ & $N=31(\%)$ & \\
\hline Age (mean \pm SD) & $51.9 \pm 22.8$ & $52.3 \pm 21.7$ & 0.943 \\
Gender & & & \\
$\quad$ Male & $15(46.9)$ & $16(51.6)$ & 0.704 \\
$\quad$ Female & $17(53.1)$ & $15(48.4)$ & \\
Resident & & & \\
$\quad$ Rural & $14(43.7)$ & $12(38.7)$ & 0.682 \\
$\quad$ Urban & $18(56.3)$ & $19(61.3)$ & \\
Constitutional symptoms & $30(93.8)$ & $29(93.6)$ & 0.976 \\
Cough & $29(90.6)$ & $28(90.3)$ & 0.968 \\
BMI $<18.5$ & $15(46.9)$ & $14(45.2)$ & 0.889 \\
Tuberculin test $>10$ mm & $27(84.4)$ & $26(83.8)$ & 0.96 \\
Sputum smear $>1+$ & $13(40.6)$ & $13(41.9)$ & 0.912 \\
Anemia* & $17(53.1)$ & $16(51.6)$ & 0.904 \\
$\uparrow$ ESR $^{* *}$ mm/h & $28(87.5)$ & $29(93.6)$ & 0.412 \\
$\uparrow$ CRP $^{* * *}$ & $24(75)$ & $22(71)$ & 0.719 \\
\hline
\end{tabular}

${ }^{*} \mathrm{Hg}<13 \mathrm{~g} / \mathrm{dl}$ in men and $\mathrm{Hg}<12 \mathrm{~g} / \mathrm{dl}$ in women.

** The normal range (Westergren method) for males is $0-15 \mathrm{~mm} / \mathrm{h}$ and for females is $0-20 \mathrm{~mm} / \mathrm{h}$.

${ }^{* * *} \mathrm{CRP}>10 \mathrm{mg} / \mathrm{L}$.

the end of the first and second months of treatment $(P=$ 0.032 and $P=0.04$ ) and a reduced CRP at the end of the first month of treatment $(P=0.03)$ versus placebo group. There was no meaningful difference in reducing of cough $(P=0.25$ and $P=0.424)$, mycobacterial clearance in sputum smear $(P=0.254$ and $P=0.15)$, decreasing rate of ESR $(P=0.561$

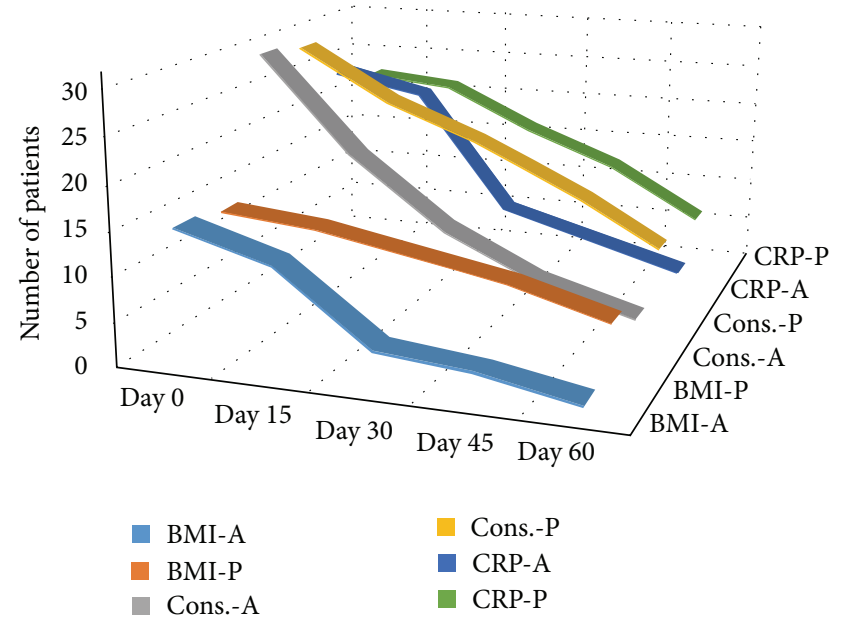

FIGURE 2: Trends in increased BMI, constitutional symptoms improvement, and decrease of CRP in patients of arginine group and placebo group.

and $P=0.258)$ and $\mathrm{Hgb}$ level $(P=0.08$ and $P=0.064)$ between 2 groups at the end of the first and second months of treatment, reduced CRP $(P=0.118)$ at the end of the second months of treatment, and final treatment success (Table 2 and Figure 2).

\section{Discussion}

This study did not show any significant reduction of cough and mycobacterial clearance in sputum smear during the first 2 months of DOTS treatment in patients receiving arginine supplementation compared to placebo group and the final treatment success was similar in two groups but results of 
TABLE 2: Clinical and laboratory findings in arginine and placebo groups at the end of the first and second months* .

\begin{tabular}{|c|c|c|c|}
\hline \multirow[b]{2}{*}{ Sign and symptom } & \multicolumn{2}{|c|}{ Group } & \multirow[b]{2}{*}{$P$ value } \\
\hline & $\begin{array}{c}\text { Arginine } \\
N=32(\%)\end{array}$ & $\begin{array}{c}\text { Placebo } \\
N=31(\%)\end{array}$ & \\
\hline \multicolumn{4}{|l|}{$\begin{array}{l}\text { Constitutional } \\
\text { symptoms }\end{array}$} \\
\hline First month & $11(34.4)$ & $19(61.3)$ & 0.032 \\
\hline Second month & $3(9.4)$ & $8(25.8)$ & 0.085 \\
\hline \multicolumn{4}{|l|}{ Cough } \\
\hline First month & $15(46.9)$ & $19(61.3)$ & 0.25 \\
\hline Second month & $3(9.4)$ & $5(16.1)$ & 0.424 \\
\hline \multicolumn{4}{|l|}{$\mathrm{BMI}<18.5$} \\
\hline First month & $4(12.5)$ & $11(35.5)$ & 0.032 \\
\hline Second month & $1(3.1)$ & $6(19.4)$ & 0.04 \\
\hline \multicolumn{4}{|l|}{ Positive sputum smear } \\
\hline First month & $14(43.8)$ & $18(58.1)$ & 0.254 \\
\hline Second month & $1(3.1)$ & $4(12.9)$ & 0.15 \\
\hline \multicolumn{4}{|l|}{ Anemia } \\
\hline First month & $6(18.8)$ & $12(38.7)$ & 0.08 \\
\hline Second month & $2(6.3)$ & $7(22.6)$ & 0.064 \\
\hline \multicolumn{4}{|l|}{$\uparrow \mathrm{ESR} \mathrm{mm} / \mathrm{h}$} \\
\hline First month & $25(78.1)$ & $26(83.9)$ & 0.561 \\
\hline Second month & $11(34.4)$ & $15(48.4)$ & 0.258 \\
\hline \multicolumn{4}{|l|}{$\uparrow \mathrm{CRP}$} \\
\hline First month & $8(25)$ & $16(51.6)$ & 0.03 \\
\hline Second month & $2(6.3)$ & $6(19.4)$ & 0.118 \\
\hline $\begin{array}{l}\text { Final treatment success } \\
\text { (end of sixth month) }\end{array}$ & $32(100 \%)$ & $31(100 \%)$ & - \\
\hline
\end{tabular}

${ }^{*}$ Categorical variables were compared using the chi-square test or Fisher's exact test where appropriate. Continuous variables were compared using the $t$-test or the nonparametric Mann-Whitney $U$ test according to data distribution.

our study demonstrate that arginine was associated with some benefits such as reduced constitutional symptoms in patients with smear-positive TB at the end of the first month of treatment. Arginine treated patients had significantly increased BMI at the end of the first and second months of treatment and a reduced CRP at the end of the first month of treatment versus placebo group. The improved BMI, constitutional symptoms, and decreased CRP may be associated with increased arginine levels, which consequently have ergogenic potential because of their role in the secretion of endogenous growth hormone and their involvement in the synthesis of creatine, L-Arginine supplementation affects on CNS function, increasing nitric oxide and strengthen the immune system [18].

Nitric oxide acts as a cytotoxic agent in pathological processes and can therefore play a central role in the regulation of immune responses [19]. Nitric oxide bioavailability is impaired in pulmonary TB in proportion to clinical severity and is associated with delayed mycobacterial clearance [20, 21]. Hypoargininemia can develop when arginine catabolism exceeds endogenous synthesis and hypoargininemia has been demonstrated in TB [22]. In addition to immunological effects, L-arginine can influence antimycobacterial cellmediated responses directly, being required for expression of the $\mathrm{T}$ cell receptor's CD3 zeta component [22]. Two trials have addressed L-arginine in $\mathrm{TB}$, testing L-arginine hydrochloride $(\mathrm{g})$ or arginine-rich food (peanuts). In the beginning, faster sputum-microscopy clearance and cough resolution were reported in the supplemented arm, but only among $\mathrm{HIV}^{-}$participants [16]. The second study reported no significant benefits overall and found higher cure rates in $\mathrm{HIV}^{+}$participants receiving the arginine-rich supplement [23]. Ralph et al. evaluated L-arginine with vitamin D as adjunctive TB therapies and at the doses evaluated, they could not demonstrate that these agents alone or in combination were associated with benefits in TB outcomes [24]. A previous study has shown that arginine supplementation led to decreased morbidity from infectious diseases in highrisk patients undergoing surgery [25]. The improved clinical outcome observed in TB patients was probably mediated by augmented production of $\mathrm{NO}$ induced by increased arginine intake. These results support a role for arginine supplementation aimed at enhancing the human antimycobacterial effect during the treatment of active TB. In our study no major side effects were reported in the arginine groups and Larginine has few adverse reactions. Nausea and diarrhea have been reported infrequently. The important limitation in this study related to the lack of evaluation of concentration of arginine and nitric oxide, short length of observation, lack of sputum culture, and small sample size. We propose that further studies be conducted to investigate in larger samples with higher doses and longer duration of L-arginine.

\section{Conclusion}

Arginine is useful as an adjunctive therapy in patients with active tuberculosis, which the effects more likely to be mediated by the increased production of nitric oxide. This study showed that arginine is beneficial as supplement treatment in patients with active tuberculosis, an effect most likely improved constitutional symptoms, weight gain, and reduction of CRP despite the lack of effect on anemia, cough, sputum smear conversion, and final treatment success.

\section{Ethical Approval}

This study was conducted according to the principles expressed in the Declaration of Helsinki and approved by the Ethics Committees at the Arak University of Medical Sciences, the Faculty of Medicine.

\section{Consent}

All study subjects were included after obtaining informed consent. 


\section{Disclosure}

This study was a thesis, extracted from the final doctoral thesis of medical student, conducted at the Arak University of Medical Sciences.

\section{Conflict of Interests}

The authors declare no conflict of interests.

\section{Authors' Contribution}

All the authors made substantial contributions to conception and design and acquisition of data and participated in drafting the paper, revising, and the final approval.

\section{Acknowledgments}

The authors would like to thank the Deputy of Research in Arak University of Medical Sciences for approving the thesis, physicians for referring, and patients for their cooperation. The Arak School of Medicine supported financially this research.

\section{References}

[1] WHO, "World health organization (WHO) library cataloguingin-publication data," Global Tuberculosis Report, 2013, http:// www.who.int/tb/publications/global_report.

[2] S. M. Morris Jr., "Arginine metabolism: boundaries of our knowledge," Journal of Nutrition, vol. 137, no. 6, supplement 2, pp. 1602S-1609S, 2007.

[3] L. Beaumier, L. Castillo, Y.-M. Yu, A. M. Ajami, and V. R. Young, "Arginine: new and exciting developments for an 'old' amino acid," Biomedical and Environmental Sciences, vol. 9, no. 2-3, pp. 296-315, 1996.

[4] J. Appleton, "Arginine: clinical potential of a semi-essential amino acid," Alternative Medicine Review, vol. 7, no. 6, pp. 512$522,2002$.

[5] B. C. Tong and A. Barbul, "Cellular and physiological effects of arginine," Mini-Reviews in Medicinal Chemistry, vol. 4, no. 8, pp. 823-832, 2004.

[6] M. Arnold and A. Barbul, "Nutrition and wound healing," Plastic and Reconstructive Surgery, vol. 117, supplement 7, pp. 4258, 2006.

[7] A. Mandal, "Do malnutrition and nutritional supplementation have an effect on the wound healing process?" Journal of Wound Care., vol. 15, no. 6, pp. 254-257, 2006.

[8] V. Bronte and P. Zanovello, "Regulation of immune responses by L-arginine metabolism," Nature Reviews Immunology, vol. 5, no. 8, pp. 641-654, 2005.

[9] S. M. Morris Jr., "Arginine: beyond protein," The American Journal of Clinical Nutrition, vol. 83, pp. S508-S512, 2006.

[10] R. Hernández-Pando, T. Schön, E. H. Orozco, J. Serafin, and I. Estrada-García, "Expression of inducible nitric oxide synthase and nitrotyrosine during the evolution of experimental pulmonary tuberculosis," Experimental and Toxicologic Pathology, vol. 53, no. 4, pp. 257-265, 2001.

[11] E. D. Chan, J. Chan, and N. W. Schluger, "What is the role of nitric oxide in murine and human host defense against tuberculosis? Current knowledge," The American Journal of Respiratory Cell and Molecular Biology, vol. 25, no. 5, pp. 606612, 2001.

[12] C. Nathan and M. U. Shiloh, "Reactive oxygen and nitrogen intermediates in the relationship between mammalian hosts and microbial pathogens," Proceedings of the National Academy of Sciences of the United States of America, vol. 97, no. 16, pp. 8841-8848, 2000.

[13] H.-S. Choi, P. R. Rai, H. W. Chu, C. Cool, and E. D. Chan, "Analysis of nitric oxide synthase and nitrotyrosine expression in human pulmonary tuberculosis," The American Journal of Respiratory and Critical Care Medicine, vol. 166, no. 2, pp. 178186, 2002.

[14] D. C. MacAllan, "Malnutrition in tuberculosis," Diagnostic Microbiology and Infectious Disease, vol. 34, no. 2, pp. 153-157, 1999.

[15] T. Schön, D. Elias, F. Moges et al., "Arginine as an adjuvant to chemotherapy improves clinical outcome in active tuberculosis," European Respiratory Journal, vol. 21, no. 3, pp. 483-488, 2003.

[16] B. Swanson, J. K. Keithley, J. M. Zeller, and B. E. Sha, "A pilot study of the safety and efficacy of supplemental arginine to enhance immune function in persons with HIV/AIDS," Nutrition, vol. 18, no. 7-8, pp. 688-690, 2002.

[17] T. Schön, J. Idh, A. Westman et al., "Effects of a food supplement rich in arginine in patients with smear positive pulmonary tuberculosis-a randomised trial," Tuberculosis (Edinburgh, Scotland), vol. 91, no. 5, pp. 370-377, 2011.

[18] M. Z. Gad, "Anti-aging effects of L-arginine," Journal of Advanced Research, vol. 1, no. 3, pp. 169-177, 2010.

[19] F. Aktan, "iNOS-mediated nitric oxide production and its regulation," Life Sciences, vol. 75, no. 6, pp. 639-653, 2004.

[20] G. Lugo-Villarino, C. Vérollet, I. Maridonneau-Parini, and O. Neyrolles, "Macrophage polarization: convergence point targeted by Mycobacterium tuberculosis and HIV," Frontiers in Immunology, vol. 2, article 43, 2011.

[21] A. P. Ralph, T. W. Yeo, C. M. Salome et al., "Impaired pulmonary nitric oxide bioavailability in pulmonary tuberculosis: association with disease severity and delayed mycobacterial clearance with treatment," Journal of Infectious Diseases, vol. 208, no. 4, pp. 616-626, 2013.

[22] A. H. Zea, K. S. Culotta, J. Ali et al., "Decreased expression of CD3zeta and nuclear transcription factor kappa B in patients with pulmonary tuberculosis: potential mechanisms and reversibility with treatment," Journal of Infectious Diseases, vol. 194, no. 10, pp. 1385-1393, 2006.

[23] T. Schön, J. Idh, A. Westman et al., "Effects of a food supplement rich in arginine in patients with smear positive pulmonary tuberculosis-a randomised trial," Tuberculosis, vol. 91, no. 5, pp. 370-377, 2011.

[24] A. P. Ralph, G. Waramori, G. J. Pontororing et al., "L-arginine and vitamin $\mathrm{D}$ adjunctive therapies in pulmonary tuberculosis: a randomised, double-blind, placebo-controlled trial," PLoS ONE, vol. 8, no. 8, Article ID e70032, 2013.

[25] R. Tepaske, H. Te Velthuis, H. M. Oudemans-van Straaten et al., "Effect of preoperative oral immune-enhancing nutritional supplement on patients at high risk of infection after cardiac surgery: a randomised placebo-controlled trial," The Lancet, vol. 358, no. 9283, pp. 696-701, 2001. 


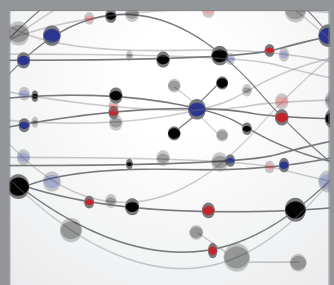

The Scientific World Journal
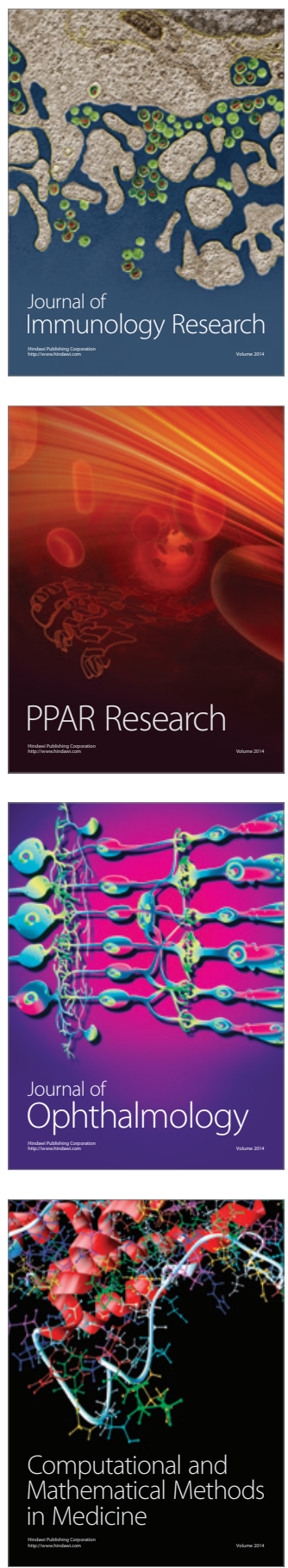

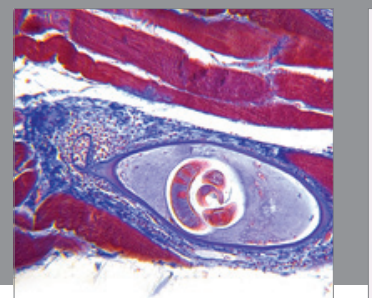

Gastroenterology

Research and Practice
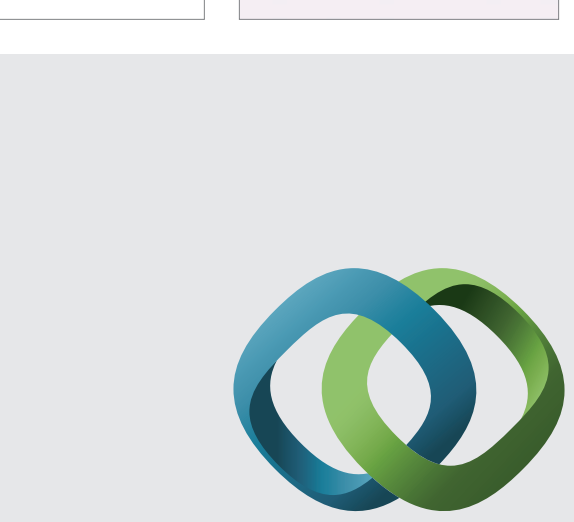

\section{Hindawi}

Submit your manuscripts at

http://www.hindawi.com
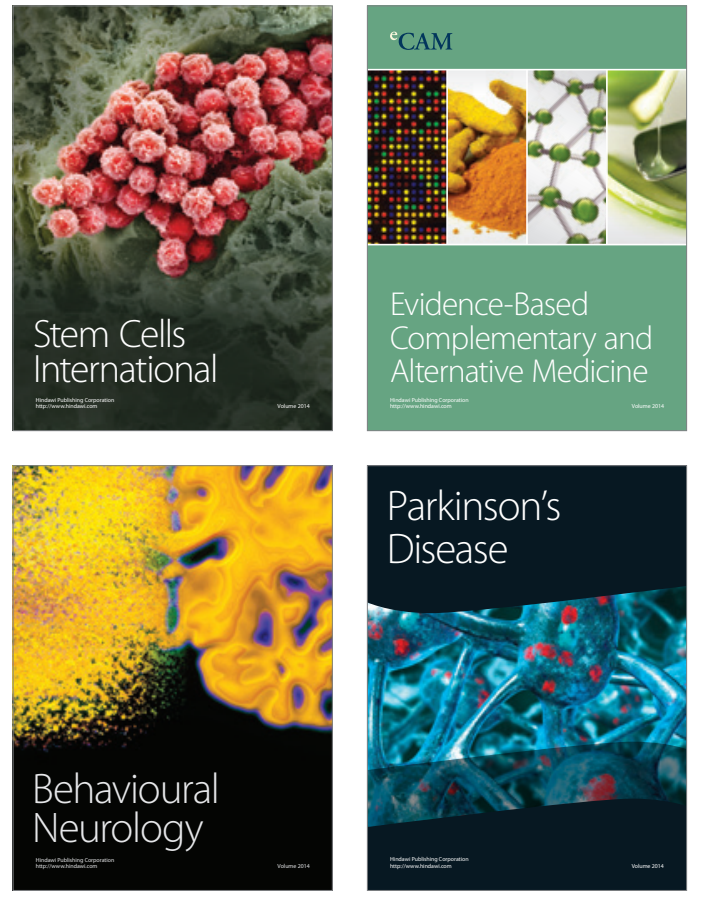
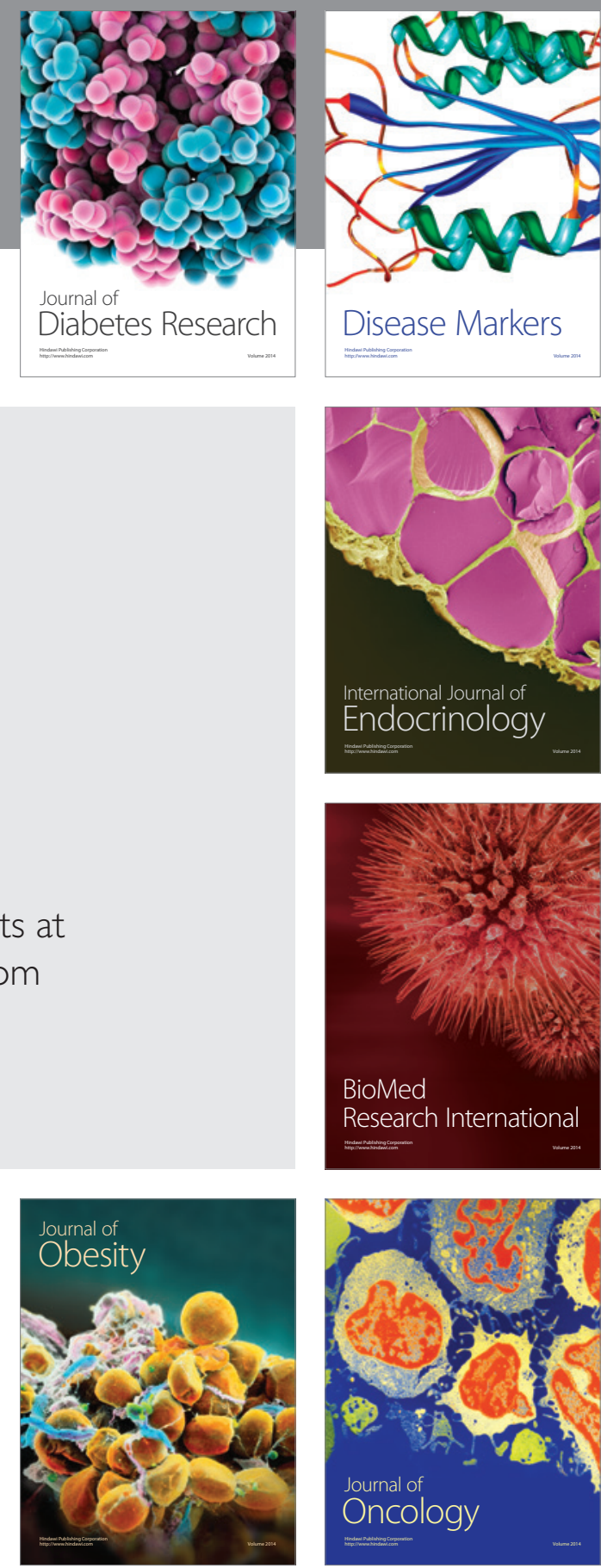

Disease Markers
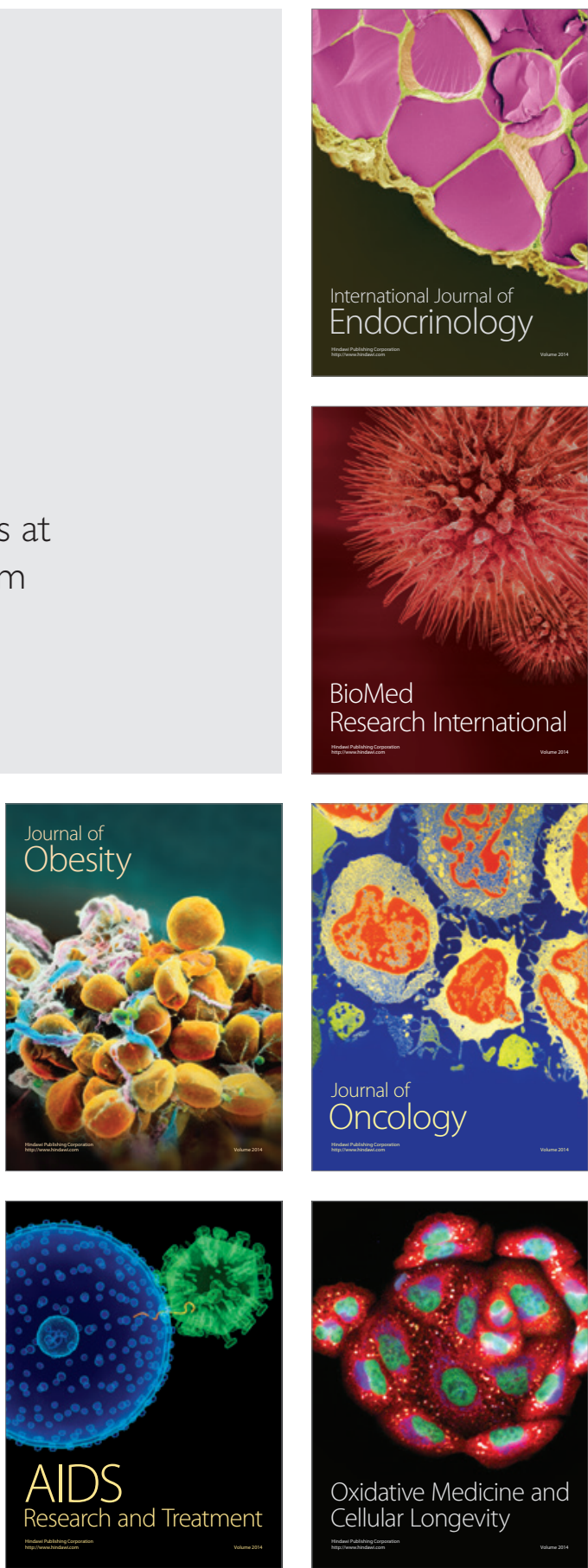